\title{
Factors Influencing Olfactory Perception of Selected Off-flavour- causing Compounds in Red Wine - A Review
}

\author{
M. McKay*, A. Buica \\ Department of Viticulture and Oenology; Stellenbosch University
}

Submitted for publication: August 2019

Accepted for publication: December 2019

Key words: Red wine, volatile phenols, IBMP, TCA, olfactory perception, taint, off-flavour

\begin{abstract}
Extensive work on the chemical aspects of off-flavour in wine has been carried out by international researchers, but not as many studies focus on the organoleptic effects. This literature review therefore has a focus on the status of the sensory aspects of compounds associated with specific off-flavours in red wine, viz. three volatile phenols, as well as 2-isobutyl-3-methoxypyrazine and 2,4,6-trichloranisole. The review discusses sources and effects of the selected compounds in red wine, and what previous workers have found pertaining to the mechanisms of the odour perception of aroma compounds, odour detection thresholds, and issues relating to the effects of the matrix. It also considers the factors that have been found to cause differences in olfactory perceptions between panellists/judges, and covers some of the work that has been carried out in characterising perceptual interactions between compounds in wine. Gaps that exist in the current literature are highlighted.
\end{abstract}

\section{INTRODUCTION}

Due to the variability of odours in wine, volatiles are the components that often best define the parameters of quality and typicality (Mozzon et al., 2016). While a complex bouquet is generally associated with good quality, wines sometimes can manifest a range of off-odours (unexpected and/or undesirable smells) as a result of the presence of specific volatile compounds that enter the wine production process from a number of different sources. These offodours, which form a continuum of perceived aromas across a broad range of odour families (Fig. 1), can then lead to a drop in perceived wine quality, and may contribute to a lack of typicality of style or cultivar profile (Parr et al., 2007).

The range and variability of taints and off-flavours in red wine obviously involve hundreds of volatiles (Rauhut \& Kiene, 2019), and it is impossible to address the impact of even a percentage of them in one review. This study therefore concentrates on compounds that have been linked to 'smoky/ burnt' (Goode, 2008; Krstic et al., 2015), 'acrid' (Hammond, 2015), 'herbaceous'/'dusty' (Heyns, 2014), and 'burnt/rubber (BR)' (Bearak, 2009) off-flavours that have been associated with, but are not unique to, South African red wine. Fig. 2 shows three examples of volatile phenols (namely guaiacol, 4-ethylphenol and ortho-cresol) and two compound from other classes: 3-isobutyl-2-methoxypyrazine and 2,4,6trichloroanisole, which have been shown to contribute to the off-flavour profile of wine.

Relationships between quality, typicality and taint are not well documented in the literature. Descriptors associated with off-odour issues in red wine can include some easily identifiable problems like oxidation (Zoecklein et al., 1995; Culleré et al., 2007), reductive or sulphur-related problems (Shutz \& Kunkee, 1977; He et al., 2013; Franco-Luesma \& Ferreira, 2016), microbial issues like 'brettiness' (Curtin et al., 2008; Romano et al., 2009; Botha, 2010; Tempere et al., 2014) or cork taint (Van Eeden, 2009; Cravero et al., 2015), and herbaceousness (Hein et al., 2009; Šuklje et al., 2012; Lapalus, 2016). One of the parameters used when discussing odours, particularly in wine research, is the odour detection threshold (or ODT). Wine researchers recognise the ODT as the lowest concentration of a compound at which individuals can reliably perceive a difference in odour stimulus, with an operational definition of $50 \%$ performance above chance (Perry \& Hayes, 2016). At its most basic level, a detection threshold is the lowest concentration of a substance in a medium at which a stimulus is detected, but not necessarily recognised (Morrison, 1982). In wine evaluation, detection thresholds are usually olfactory or taste related, but the use of the tactile sense is also important in mouthfeel, such as astringency and 'spritz' or mousse in sparkling wines (Le Barbé, 2003). The concentrations of volatiles reaching olfactory receptors can range from levels well below threshold (infra-threshold), where no aroma is perceived, to levels well above threshold (supra-threshold), where the smell is obvious. The assumption is that tainted wines will contain specific problematic compounds at levels above their given ODTs. Similarly, if, on chemical analysis, a malodourous compound is found to be present at levels below its ODT in a wine, the compound will not be perceived 


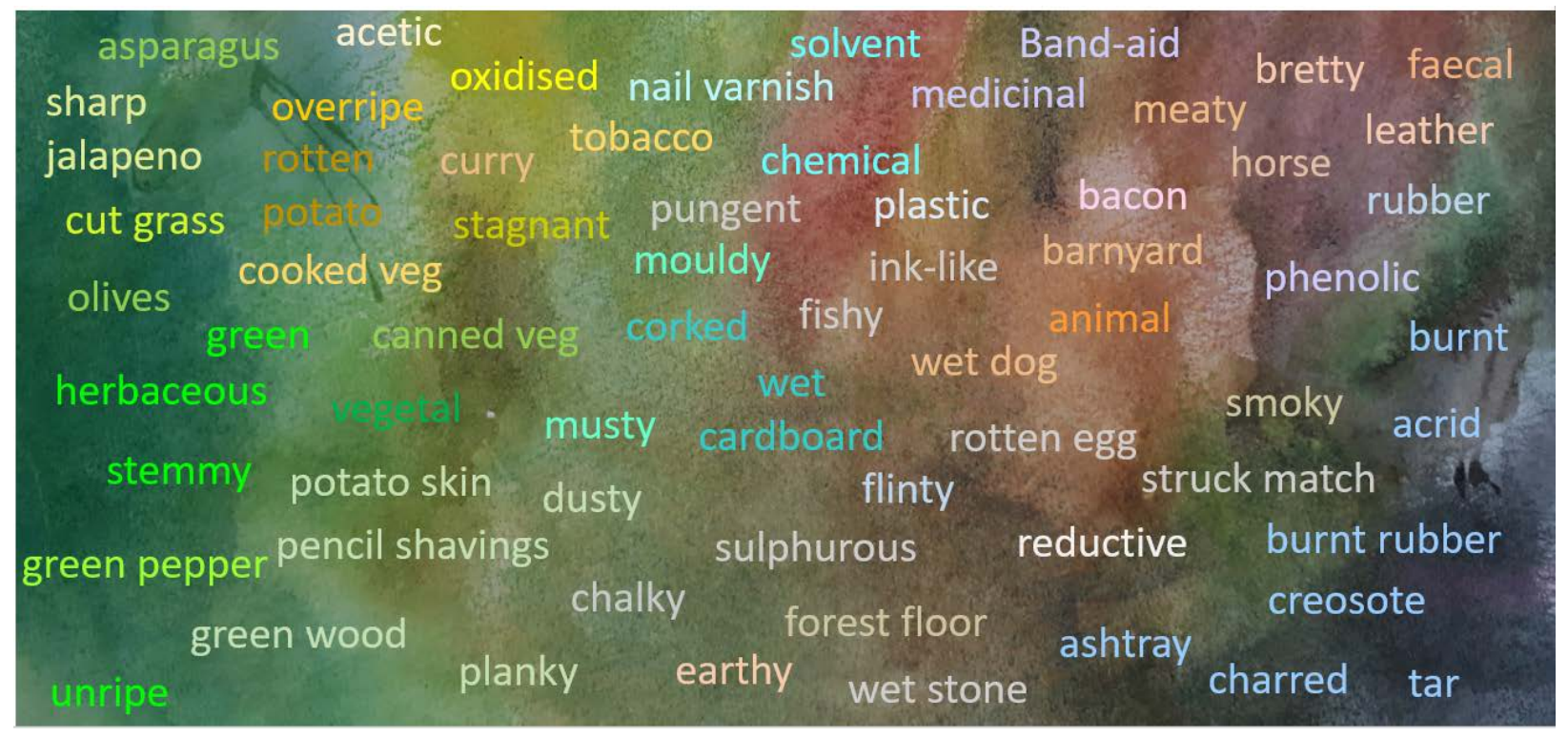

FIGURE 1

Visual representation of a possible continuum of off-odours in wine.

a)<smiles>COc1ccccc1O</smiles>

d)<smiles>COc1nccnc1CC(C)C</smiles>

b)<smiles>Cc1ccccc1O</smiles><smiles>COc1c(Cl)cc(Cl)cc1Cl</smiles>

c)<smiles>CCc1ccc(O)cc1</smiles>

\section{FIGURE 2}

Selected taint-causing compounds in red wine: a) guaiacol, b) ortho-cresol, c) 4-ethylphenol, d) 3-isobutyl-2methoxypyrazine, e) 2,4,6-trichloroanisole.

as a threat to wine quality. This is the rationale behind the concept of odour activity values (OAVs), a measure that is frequently used by wine researchers, oenologists and flavour chemists (Atanasova et al., 2005b; Styger et al., 2011; Ferreira, 2012; Yang et al., 2015). However, it is frequently the case that the OAVs or ODTs do not fully elucidate what is happening in the aroma profile of the wine (Panzeri, 2013; Lapalus, 2016; Wilson, 2017), so sensory evaluation using an appropriate sensory methodology is essential (Lawless \& Heymann, 1998; Meilgaard et al., 2015).

\section{Volatile phenols}

Volatile phenols (VPs) are a group of compounds associated with a complex range of descriptors in wine (Boidron et al., 1988; Parker et al., 2012; Lorrain et al., 2013), some of which are negative. The class of VPs includes sub-groups such as ethylphenols, vinylphenols, syringols, cresols and xylenols. The VPs most commonly found in red wine are 4-ethylguaiacol (4-EG), 4-ethylphenol (4-EP), 4-methylguaiacol (4-MG), vinylphenols, guaiacol, eugenol, and vanillin (Chatonnet et al., 1992; Spillman et al., 1998; Kennison et al., 2008). At low levels, these compounds can add pleasant complexity to the wine aroma (Francis \& Newton 2005), but higher levels are undesirable and usually considered to cause an off-flavour or taint (Boidron et al., 1988, Kennison et al., 2008). VPs in wine may come from a number of sources, including yeast fermentation (Romano et al., 2009; Weiss, 2014) and wood maturation (Boidron 
et al., 1988; Prida \& Chatonnet, 2010). Sefton (1998) and Wirth et al. (2001) reported that guaiacol and 4-MG occurred naturally in the fruit and leaves of Shiraz, Merlot and Cabernet Sauvignon. Ristic et al. (2015) showed that control Shiraz wines had higher levels of guaiacol compared to those of Merlot.

Guaiacol and 4-MG are derived from oak lignin degradation products and therefore are commonly found in wines that have been aged in oak barrels (Pollnitz et al., 2000; Singh et al., 2011). Extraction from oakwood by wine usually is in the range of $10 \mu \mathrm{g} / \mathrm{L}$ to $100 \mu \mathrm{g} / \mathrm{L}$ and $1 \mu \mathrm{g} / \mathrm{L}$ to $20 \mu \mathrm{g} / \mathrm{L}$ for guaiacol and 4-MG respectively (Pollnitz et al., 2004) and, depending on the matrix and extraction level, they can contribute to 'toasty' aromas associated with wood maturation. The cresols, as well as 3,4-dimethylphenol (3,4DMP), guaiacol and 4-EP, have also been linked to lignin pyrolysis during the toasting of oak barrels (Etievant, 1981; Cadahía et al., 2003; Fernández de Simón et al., 2008).

Volatile phenols can also be produced in red wine from the bioconversion of hydroxycinnamic acids in grapes (Fugelsang \& Edwards, 2007), notably by yeast of the Brettanomyces genus (Chatonnet et al., 1992; Romano et al., 2009). If produced in large enough concentrations, this may lead to the so-called 'brett' taint, also called 'bretty' and 'brettiness'. VPs responsible for this taint include 4-EP, 4-EG and 4-ethylcatechol (4-EC), which are reduced from their respective vinylphenol derivatives (Malfeito-Ferreira et al., 2009).

Other sources of VPs in food products may come from motor exhausts and residential emissions in highly populated areas (Perrone et al., 2014). Industrial hazes (Goldammer et al., 2009) have also been noted as sources, with many aromatic compounds identified in air pollution.

Although VPs, as noted, may derive from a number of sources, a lot of research in recent years concerning VPs has centred on smoke taint (Krstic et al., 2015), which is the off-odour that results from the exposure of grapes to bushfire smoke. Work related to smoke taint in wine has followed a logical progression of discovery over the years since it started, with Australian researchers leading the field. Kennison et al. $(2008,2009,2011)$ demonstrated a direct association between grapes exposed to smoke during the growing season and the presence of VPs in Merlot juice. The effects of two of the key compounds associated with smoke taint in wine (guaiacol and 4-MG) have been well described (Kennison et al., 2011; De Vries et al., 2016), and include 'burnt', 'smoky' and 'ashy' aromas and flavours, despite the fact that they may be present at lower levels in smokeexposed grapes than they are after the maturation of wine in oakwood, indicating that these negative perceptions may be due to the influence of other factors in the wine. Studies focusing on the chemical measurement of concentrations of these and other VPs (including the cresols, syringol and 4-methyl syringol) in smoke-tainted grapes and wines and VP glycosides (Hayasaka et al., 2010; Wilkinson et al., 2011; Kelly et al., 2014; Noestheden et al., 2018) are extensive and ongoing. Wilkinson et al. (2011) compared methods of analysis of VPs and their glycoconjugates in grapes and wine. Kelly et al. (2012) assessed the exposure of grapes to smoke from vegetation with varying lignin composition and the accretion of lignin-derived putative smoke taint compounds in wine. Fudge et al. (2011) investigated the effect of reverse osmosis and solid phase adsorption on ameliorating smoke taint in wine, and Kelly et al. (2014) examined extraction effects of winemaking practices on VPs, as well as sensory profiles associated with them (Kelly et al., 2014; Kelly \& Zerihun, 2015). Although it was shown that juice from smoke-exposed grapes seldom contains significant levels of VPs, by the time fermentation has completed, free VP levels may have risen tenfold and, in the case of guaiacol, a hundredfold (Kennison et al., 2008) due to the activity of yeast and bacterial enzymes active during fermentation. Krstic et al. (2015) reviewed smoke taint-derived VPs and their glycosidic metabolites in grapes and vines as biomarkers for smoke exposure, and their role in the sensory perception of smoke taint. Ristic et al. (2017) investigated the effect of bottle ageing on the release of VPs during maturation. Hayasaka et al. (2010) also assessed the impact of smoke exposure in grapes, quantifying VP glycosides.

As forest fires close to vineyards are becoming more frequent (Fried et al., 2004; Parker et al., 2012; Wolf, 2018), wine producers need to be aware of at what concentration smoke-related compounds affect the sensory properties of a particular wine. Smoke particles are known to travel many kilometres from their source and settle over large areas (Goldammer et al., 2009), which may affect crops including grapevines. Thus, the role of VPs in smoke taint in wine (Fig. 3), as well as other agricultural crops, is a primary focus, as this phenomenon has a severe economic impact on producers, and is unlikely to decrease, given the effects of global warming (Strydom \& Savage, 2016).

The effects of VPs on the aroma profile of red wine have long been known. They have been linked to a number of other off-odour issues on a continuum of aromas in red wine, including the previously mentioned 'brettiness' and 'smoke taint'. Chatonnet et al. (1992) define the effect of volatile phenols produced by microorganisms in wine during ageing as an off-flavour known as 'phenole' or 'phenolic' ('disagreeable animal, stable') odour. In a large study characterising the odours of 30 alkylated volatile phenols in air, Czerny et al. (2011) noted that phenol itself was 'inklike' in aroma, and mono-alkylated phenols were generally described as 'medicinal', 'ink-like', 'leather', 'horse' and smoky'. The VPs 4-EG and 4-EP are associated with 'medicinal', 'horse/leather' and 'barnyard' characteristics, and although they can impart smoky aromas/flavours, they are not considered markers of smoke taint. Dimethylated phenols have been described as 'burnt', with trimethylated phenols distinguishable as having 'smoky' and 'rubber' characteristics, in addition to the previously listed attributes. Czerny et al. (2011) observed that the phenolic hydroxyl group was an important factor in the odour characteristics of this class of compounds, as the corresponding toluenes were almost odourless. Aroma descriptors have been established in water for a number of the volatile phenols (Czerny et al., 2008), including guaiacol, the furfurals and 4-ethyl and vinyl phenol. Some of these compounds are a normal part of a complex wine aroma profile when present at low levels, but can cause problems at higher concentrations because they suppress fruitiness (Atanasova et al., 2005a; 

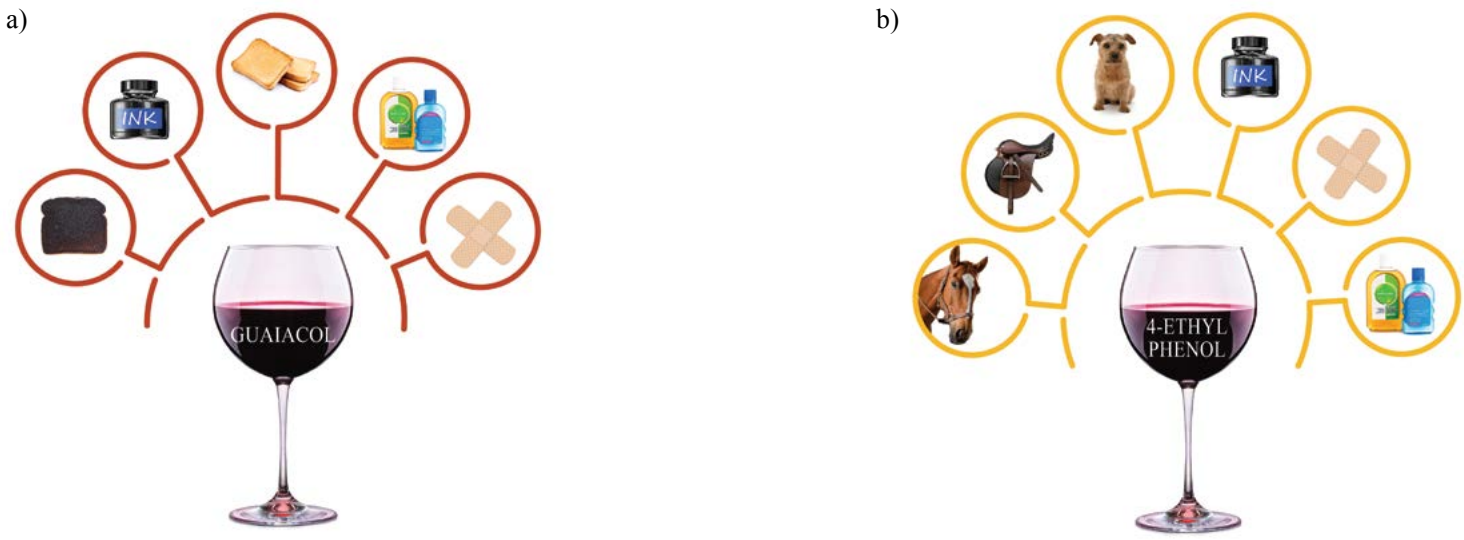

FIGURE 3

Visual representation of off-odours that may be perceived due to the presence of two volatile phenols, a) guaiacol ('burnt', 'phenolic/ink-like', 'toasty', 'medicinal' and 'Elastoplast'TM) and b) 4-ethyl phenol ('horsey', 'leather', 'animal', 'phenolic/ ink-like', 'Elastoplast'TM and 'medicinal'), in red wine.

Ferreira, 2012) and impart smoky, charred or burnt aromas (Kennison, 2011). Guaiacol forms part of the 'woody' family of descriptors (Noble et al., 1987), and exhibits 'burnt', 'smoky' and 'sweet-burnt' characteristics. At low levels, it is not known to cause off-flavours in red wine. Parker et al. (2012), however, did show that guaiacol, 4-methylsyringol (4-MS), 4-MG, phenol and $o$ - and $m$-cresol were positively correlated with both smoke aroma and ashy aftertaste. Many of the VPs in their study were positively associated with a 'medicinal' attribute, with syringol, $o$-cresol and 4-methylsyringol being large contributors to smoke taint. Smoke-related sensory attributes were well predicted by the volatile phenol data in their study.

In later work, Parker et al. (2013) described the aroma of $o$-cresol as 'medicinal' and 'smoky'. Boidron et al. (1988) have also described it as 'tar' (bitumen)-smelling, in a significant study of the aroma compounds found in wine and derived from oak, which has been substantiated by Panzeri (2013) and De Vries et al. (2016). The study by Parker et al. (2013) also indicated that volatile phenols and their glycosides produce an undesirable smoke flavour in the affected wines. Descriptors for 4-EP, the compound most closely associated with 'brettiness' in wine, include 'horsey', 'leather', 'Band-aid' or 'Elastoplast ${ }^{\mathrm{TM}}$ ' (Oelofse et al., 2009), 'medicinal', 'smoky' (Kennison et al., 2008, 2011), 'faecal' and 'horse-stable' (Czerny et al., 2011). Aroma attributes used to describe wines made from grapes exposed to smoke also include 'burnt rubber', leather', 'disinfectant' and 'smoked meat' (Kennison et al., 2009).

\section{3-Isobutyl-2-methoxypyrazine (IBMP)}

Consumers rarely appreciate red wines with pronounced herbaceous flavours (Mozzon et al., 2016). If 'greenness' is present, products are described as possessing immature character, lacking refinement and elegance, and having reduced fruit intensity. The 'herbaceous' and 'vegetative' character has also been shown to detrimentally affect palate structure and give a 'green tannin' mouthfeel, but evidence is anecdotal and there is little in the primary literature to back this up. Parr et al. (2007) noted that, even with
Sauvignon Blanc, a cultivar renowned for 'greenness', not all 'green' characters (notably 'leafy', 'stalky', or 'vegetal') are positively correlated with typicality or good varietal definition.

Although it is well known that methoxypyrazines, and specifically 3-isobutyl-2- methoxypyrazine, are responsible for 'bell pepper' and 'herbaceous' notes in wine (Allen et al., 1996; Marais \& Swart, 1999), little has been written concerning the interaction of these compounds with other taint compounds in wine. Lapalus (2016) characterised the sensory attributes and chemical composition of thirteen selected South African Cabernet Sauvignon wines and found that supra-threshold concentrations of IBMP correlated with 'fresh green' and 'gherkins/jalapeno' attributes (Fig. 4). However, 'eucalyptus/mint' and 'bay leaves' were poorly explained by the compositional data, which warrants further investigation. Mozzon et al. (2016) emphasise the critical importance of understanding the origins and causes of these 'green' off-flavour characters in order to reduce or avoid these olfactory qualities in wines.

\section{2,4,6-Trichloroanisole (TCA)}

In wine, 2,4,6-trichloroanisole (TCA) is known to be the main compound responsible for 'cork taint' (Buser et al., 1982), and has been described as having a 'musty' (Griffiths, 1974), 'mouldy' and 'damp cardboard' odour (Cravero et al., 2015).

TCA is a product of fungal activity, and is an easily recognised compound because of its distinct odour and low sensorial threshold (Sefton \& Simpson, 2005). The off-flavour has considerable economic impact due to the rejection of wine by consumers (Van Eeden, 2009), even if the taint is present at only very low levels. Tempere et al. (2017) noted that, amongst wine defects, TCA has a specific impact on wine perception: in addition to giving the wine an unpleasant odour (Fig. 5), it has a strong masking effect on fruity notes.

Despite the sensorial 'notoriety' of the compound in wine and its low threshold levels, studies involving TCA focus mainly on the measurement of the compound in tainted 


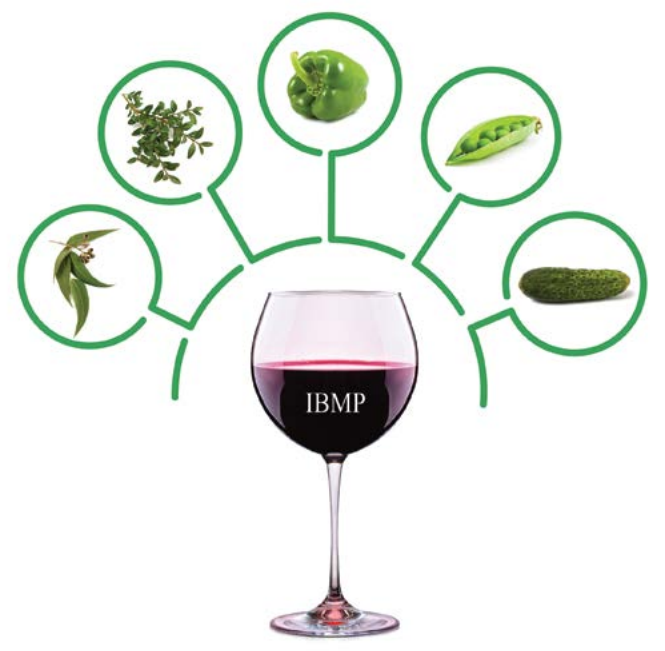

FIGURE 4

Visual representation of some off-odours that may perceived in red wine due to the presence of 3-isobutyl-2-methoxypyrazine (IBMP) ('green', 'herbaceous', 'green/bell-pepper', 'green bean', 'gherkin').

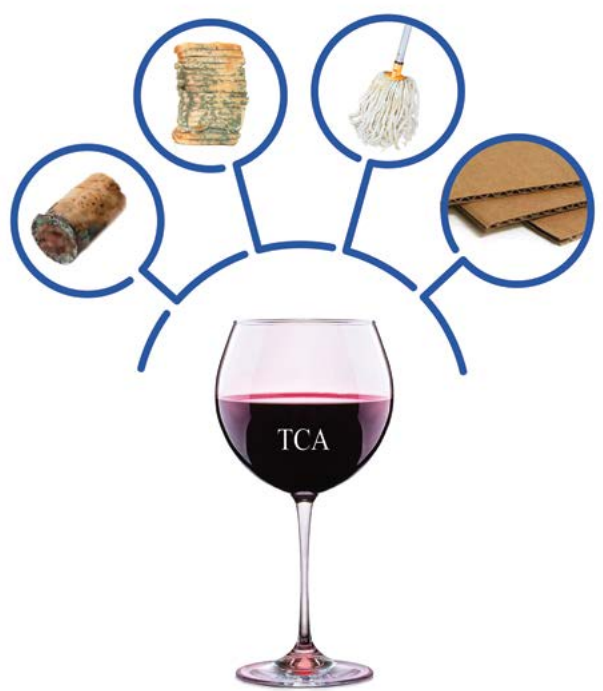

FIGURE 5

Visual representation of some off-odours that may be perceived in red wine as a result of the presence of 2,4,6-trichloroanisole (TCA) ('cork taint', 'mouldy', 'stagnant/dish water', 'wet cardboard').

wines (Buser et al., 1982; Boidron et al., 1988; Pollnitz et al., 1996; Prescott et al., 2005) and corks (Pollnitz et al., 1996; Taylor et al., 2000; Álvarez- Rodríguez et al., 2002), and it is difficult to find studies in which its sensory effects are tested formally in combination with other compounds or in different matrices.

\section{Factors affecting the olfactory perception of off-odour compounds in red wine}

Sensory thresholds are based on the minimum amount of compound added to a clean control that elicits, from a human subject, a recognition of difference in sensory quality between sample and control (Lawless \& Heymann, 1998). Usually, odour threshold determinations in solutions are based on the use of a dilution series that presents the odour compound diluted at precise ratios to a panel of assessors. Lawless and Heymann (2010) later stated that threshold studies relying on a " $50 \%$ perceive a difference test" are arbitrary and empirical, and there was thus little scientific basis for such a test. Some authors have gone as far as to suggest it may be futile to invest time and money in threshold studies (Meilgaard et al., 2015). However, researchers do need some sort of measure against which to quantify the effects of treatments, and the threshold approach, in the matrix in which the study is to be conducted and using as many subjects as possible, has been shown to be simple, reliable and, despite its shortcomings, still the best strategy available (Meilgaard et al., 2015). Some authors use the so-called best estimate threshold (BET), with which the 
individual BET is determined as the geometric mean of the maximum concentration of a compound in solution eliciting a negative response (not recognised as different from a control), and the next highest concentration (recognised as different from the control) (Zhang et al., 2016). The group BET is calculated as the geometric mean of the individual BETs.

As indicated previously, a parameter used frequently in wine evaluation is the 'odour activity value' (OAV). In the literature, the stimulus presented by a specific odorant is often expressed in terms of an OAV, which is defined as the ratio between the concentration of the compound in the wine and the detection threshold for that compound (Prida \& Chatonnet, 2010). OAVs seem to be a relatively simple way for determining the potential sensory impact of chemical compounds, as a value $>1$ is considered 'odour-active' (Prida \& Chatonnet, 2010; Ferreira, 2012), but they often do not correlate with intensity of aroma perception, and they cannot predict how various compounds are perceived at different concentrations, and in different matrices. If OAVs are assigned and applied arbitrarily across different matrices, they will rely solely on the physicochemical parameters of the solution, and not take into account the other factors involved in sensory perception (Audouin et al., 2001). It is unlikely that they will accurately reflect the complexity of the effects of the solution on the sensory perception of target aroma compounds.

ODTs for volatile phenols vary widely between individual compounds and matrices. Guaiacol and 4-MG exhibited the lowest odour-detection thresholds in a red wine matrix (75 mg/L and $65 \mathrm{mg} / \mathrm{L}$ respectively) of all the phenols tested by Boidron et al. (1988). Eisele and Semon (2006) reported a very low 'best estimate threshold' (International Standards Organisation [ISO], 2002) for guaiacol, of $0.48 \mu \mathrm{g} / \mathrm{L}$ in water. Eisele and Semon (2006) also noted that there was about a 500-fold range in guaiacol detection between panellists, with some individuals exhibiting a best estimate threshold (BET) as low as $10 \mathrm{ng} / \mathrm{L}$. Parker et al. (2012) reported a BET for guaiacol detection in red wine of $23 \pm 0.8 \mu \mathrm{g} / \mathrm{L}$, and 27 $\pm 0.6 \mu \mathrm{g} / \mathrm{L}$ for guaiacol flavour (in mouth). Simpson et al. (1986) reported a lower ODT of $20 \mu \mathrm{g} / \mathrm{L}$ for guaiacol in white wine.

It is difficult to find any sensory information in the primary literature regarding ODTs for the cresols. Some work has been done in whisky, but the only current winerelated references concern the appearance of cresols in wine after smoke events in the vineyard. Boidron et al. (1988) gave the 'bitumen'-smelling $o$-cresol a sensory threshold of $800 \mu \mathrm{g} / \mathrm{L}$ BET, which seems extraordinarily high, but the study was looking specifically at wooded wines, and heavily toasted wood is very likely to have elevated levels of pyrolysis products. The panel would also have been exposed to 16 aromatic wood-derived compounds (10 of which were VPs), and possibly could have suffered from sensory fatigue or saturation. Parker et al. (2012) reported a BET for $o$-cresol odour, through a formal sensory process with 22 assessors, of $31 \mu \mathrm{g} / \mathrm{L}$ in model wine (alcohol solution), and $62 \pm 0.8 \mu \mathrm{g} / \mathrm{L}$ for $o$-cresol in 'base red' wine. This group also determined the thresholds for other cresols, and found $m$-cresol had the lowest BET, of $20 \mu \mathrm{g} / \mathrm{L}$.
The third VP, 4-EP, is associated with 'brettiness' and 'medicinal, Band-aid' smells (Oelofse et al., 2009), as well as 'leather/ horse' and 'bacon/meatiness' (Boidron et al., 1988; Chatonnet et al., 1992; Krstic et al., 2015). It has complex effects in wine. The detection threshold determined by Chatonnet et al. (1992) is commonly cited, which is $130 \mu \mathrm{g} / \mathrm{L}$ in water, $440 \mu \mathrm{g} / \mathrm{L}$ in model wine solution, and $605 \mu \mathrm{g} / \mathrm{L}$ in red wine. In Chatonnet's study, which focuses on the microbial origin of phenols, thresholds were defined as the minimum concentration below which $50 \%$ of 70 panellists failed to distinguish the sample from a control, as described by Boidron et al. (1988) in their study of the effects of wood. For each substance studied and its mixture, the perception threshold of each taster was determined in a standard red wine (this was called a 'recovery threshold') by a triangular directional test. Curtin et al. (2008) determined the ODTs for 4-EP, 4-ethylguaiacol (4EG) and 4-ethylcatechol (4EC) in a study on 'brett' character in red wine. They realised the importance of a matrix effect on ODTs and used a 'neutral' wine, an 'oaky' wine and a 'green' wine. Unsurprisingly, given the more complex aroma of the 'oaky' wine, the ODTs were found to be significantly higher in 'oaky' wines, and slightly higher in 'green' wines, than in 'neutral' wines. The ODT of 4-EP was $368 \mu \mathrm{g} / \mathrm{L}$ in the neutral wine, $425 \mu \mathrm{g} / \mathrm{L}$ in the 'green' matrix, and $569 \mu \mathrm{g} / \mathrm{L}$ in the 'oaky' wine. No details of the method used for the determination of detection thresholds were included in the publication. In a later study, Botha (2010) determined the ODT of 4-EP to be $201 \mu \mathrm{g} / \mathrm{L}$ (median value), and $221 \mu \mathrm{g} / \mathrm{L}$ using the ASTM method, in Pinotage. According to Escudero et al. (2007), 4-EP falls in the same semantic category as woody odorants, and in wooded wines, the wood character may mask, or incorporate, the aroma character of 4-EP, making it more difficult to detect as a specific character (leather/horse/medicinal). This is in agreement with the findings of Curtin et al. (2008), and seems to explain the very high threshold found by Chatonnet et al. (1992). Botha (2010) ascribes the lower detection threshold in her study to the fact that she used unwooded Pinotage.

IBMP is often found in wine at concentrations that are above its odour threshold (Allen et al., 1996; Roujou de Boubée et al., 2000). Low levels contribute to the aromatic complexity of red wines (Roujou de Boubée et al., 2000), but higher levels are perceived as 'dustiness', 'greenness' or 'herbaceousness', and are associated with a lack of ripeness (Šuklje et al., 2012). Higher levels are seen as detrimental to red wine quality (Allen et al., 1996; Roujou de Boubée et al., 2000). It is difficult to find information in the literature on the determination of odour thresholds for methoxypyrazines. They are strong-smelling compounds, do not break down easily, and pose challenges in analysis (Alberts et al., 2013). A further challenge to evaluation is posed by the fact that people have very different sensitivities to methoxypyrazines: Shibamoto (1986) determined odour thresholds of 46 pyrazines in water using a panel of seven males and found that compounds were detected across a very wide range, from $0.01 \mu \mathrm{g} / \mathrm{L}$ to $6.00 \mathrm{mg} / \mathrm{L}$. The author did not, however, test 2-isobutyl-3-methoxypyrazine. Marais and Swart (1999) established the effect of the lowest levels of addition of IBMP (2 ng/L and $4 \mathrm{ng} / \mathrm{L})$ to Sauvignon Blanc 
wine as 'dustiness' and 'grassiness' respectively. This was not conducted as a full, formal sensory determination, as only eight judges were used. The effect in red wine was not tested. French studies of Cabernet Sauvignon and Cabernet Franc production in Bordeaux and the Loire in 1991 and 1992 showed that IBMP was the main contributor to vegetal aroma (Roujou de Boubée et al., 2000). The threshold of detection in wines was determined by comparing IBMP concentrations of 50 red Bordeaux and Loire wines from different vintages and grape varieties, using the intensity of the 'bell pepper' character as perceived on tasting. Through this, the threshold value, which rather seems to be a recognition threshold in the context of that study, and not a perception threshold, was estimated to be $15 \mathrm{ng} / \mathrm{L}$. This estimate of threshold value does not seem to have been confirmed by any further formal sensory studies. A study by Alberts et al. (2013), used odour detection thresholds from a 1996 study by Allen et al., to estimate the flavour contribution of IBMP, and stated that a 'combined concentration' (assuming an additive effect / positive interaction) of $4 \mathrm{ng} / \mathrm{L}$ to $8 \mathrm{ng} / \mathrm{L}$ will make the 'herbaceous' or 'vegetative' aroma evident in white wine, while the 'optimum concentration for Sauvignon blanc wine has been described as $8 \mathrm{ng} / \mathrm{L}$ to $15 \mathrm{ng} / \mathrm{L}$ '. Allen et al. (1996) argued that sensory perception at concentrations $>30 \mathrm{ng} / \mathrm{L}$ are considered overpowering and out of balance.

Lapalus et al. (2016) investigated the relationship between the volatile composition and sensory properties in 13 mono-varietal Cabernet Sauvignon wines produced in South Africa. The wines were selected to represent a broad range of fruity and herbaceous sensory attributes and were assessed by descriptive analysis (DA). The statistical treatment by multiple factor analysis (MFA) of both compositional data and sensory data showed that, amongst other compounds, IBMP levels predicted some but not all of the aroma attributes used to describe the selected wines. Mozzon et al. (2016) noted that a deeper understanding of the origin of these herbaceous characters is needed and, perhaps more importantly, a prediction of their effect on the finished wine.

It is difficult to find information on formal sensory detection threshold determinations of TCA, but Young et al. (1996) determined the taste and odour threshold concentrations in water for various anisoles, using dilution series and panels comprising a minimum of six specially selected and trained assessors. They found the geometric mean odour threshold concentration for TCA in water from six panellists to be $0.9 \mathrm{ng} / \mathrm{L}$, and the lowest concentration at which 'an odour' was detected to be $0.08 \mathrm{ng} / \mathrm{L}$. Tempere et al. (2017) confirmed that the distribution of the individual detection thresholds of TCA in red wine by panellists covered a wide concentration range. Studies seem to confirm this, as ODTs for trained assessors ranged from 0.03 to 1 or $2 \mathrm{ng} / \mathrm{L}$ in water (Griffiths, 1974), and up to $4 \mathrm{ng} / \mathrm{L}$ in a white wine (Sefton \& Simpson, 2005). In their study, Tempere et al. (2017) determined that a level of $0.13 \mathrm{ng} / \mathrm{L} \mathrm{TCA}$ in red wine was considered 'low', and 5 ng/L was considered 'high' based on concentrations frequently found in contaminated red wines. Mazzoleni and Maggi (2007) also noted that the detection threshold of TCA varies widely, depending on the organoleptic characteristics of the matrix, and the person perceiving it. These authors tested the detection of TCA with 14 panellists in seven different red wine cultivars and found that the compound was perceived by $>50 \%$ of the panellists at either 10 or $15 \mathrm{ng} / \mathrm{L}$, depending on the matrix. Prescott et al. (2005) established a much lower 'consumer rejection threshold' of TCA in Chardonnay, of $3.1 \mathrm{ng} / \mathrm{L}$ and $3.7 \mathrm{ng} / \mathrm{L}$, depending on the panel.

Takeuchi et al. (2013) investigated off-flavour substances generated naturally in foods/beverages and showed that TCA was detected in a wide variety of foods and beverages surveyed for odour losses. These authors observed that, even at very low levels, TCA inhibited ciliary transduction channels in single olfactory receptor cells, and showed slow kinetics in its inhibitory effect on plasma membranes. The specificity and efficacy of the masking effect of TCA was tested at infra (sub)- and supra-threshold concentrations. Tempere et al. (2017) used a simplified model of a binary mixture for in-depth analysis of the masking effect of TCA. Their results provided experimental confirmation that constituents in non-perceptible concentrations of TCA influence the perceived quality of mixtures of odorous compounds, and confirmed the work done by Takeuchi et al. (2013) on interactions taking place at the receptor level.

\section{Matrix effects on olfactory perception of taint compounds}

More than a thousand volatile compounds have been identified in wine. To be perceived, these aroma compounds need to volatilise from the matrix into the headspace of a glass and reach the olfactory epithelium of the taster (Cameleyre et al., 2018). From a physicochemical point of view, this release depends on the composition of the matrix, as volatility can be affected by the ionic strength of the solution, as compounds can form weak physical bonds with the solvent on the basis of polarity. If polarity changes (for example, with \% ethanol), the volatility of the compounds changes, which then affects the partition coefficient of the compound between the liquid and gas phase (Vilanova \& Oliveira, 2012). Matrix effects on the perception of the aroma of solutions are thus important. The lack of repeatability in studies of wine aroma is unsurprising, as odour thresholds used by wine researchers are often previously established in matrices that are not appropriate to the study undertaken. Perry and Hayes (2016) emphasise the strong need to carefully consider the composition of the delivery matrix when determining and comparing threshold estimates across studies. For example, a researcher might use the ODT for a volatile phenol that has been 'confirmed' in water or model wine for a study in red wine and find that the perceptual effects are not repeatable. This is confirmed by the work of other authors, who have found that the thresholds determined in wine are usually significantly different to those determined in model solution or water (Le Berre et al., 2008; Botha, 2010). Even within a broad category (white or red), the wine style and choice of cultivar may alter detection thresholds (Martineau et al., 1995; Jackson, 2014), but evidence from formal studies looking at this aspect is hard to find. In wine, even something as obvious as $\% \mathrm{v} / \mathrm{v}$ alcohol can affect the perception of thresholds of odour compounds, but surprisingly few studies exist to examine this aspect. As alcohol percentage increases, the volatility of a number of compounds decreases, as most 
aroma compounds are fairly hydrophobic and therefore, if more alcohol is present, they will stay in solution (Goldner et al., 2009). Thus, wines with a higher $\% \mathrm{v} / \mathrm{v}$ alcohol may be less aromatic, or totally different in aroma, from those with lower alcohol concentrations. Petrozziello et al. (2014) found that polyphenols and ethanol have a significant influence on the olfactory perception of 'brett'-tainted wines, seemingly reducing the volatility of 4-ethylphenol.

Another factor affecting olfactory perception of odours is the concentration of other odorants in the matrix. Wilson et al. (2018) showed that the perception of thiols was affected by the volatile and non-volatile wine matrix. Tempere et al. (2016b) observed that both supra- and subthreshold concentrations of off-flavour components may change the perception of odorous mixtures. They looked at the impact of infra- and supra-threshold concentrations of ethylphenols on wine, and found that both sub- and supraliminal concentrations of off-flavours not only change the 'hedonic valence' (positive or negative character) of the perception, but also have a masking effect on fruity notes. Kaeppler and Mueller (2013) noted that, in olfaction, the quality and intensity of a compound interact considerably and a shift in one dimension is often accompanied by a shift in another dimension; to quote: "Whereas a colour keeps its basic quality (blue) with increasing or decreasing intensity (light blue, dark blue), odours often change their quality with higher or lower concentrations".

Robinson et al. (2009) showed that glucose increased the concentration of volatiles in the headspace of a wine, whereas an increasing ethanol concentration was negatively correlated with the headspace partitioning of volatiles. The reduction of headspace concentration of volatiles suggests that higher ethanol concentrations may suppress 'fruity' attributes in wine. This ties in with work by Pineau et al. (2009), who carried out sensory reconstitution tests and established that very small variations in the concentrations of certain ethyl esters were perceivable in de-aromatised red wine and affected the red- and blackberry aromas. In fact, an increase of as little as $1.3 \%$ in the concentration of ethyl 2-methyl propanoate modified the assessors' aromatic perception of the matrix. In model wine, recognition tests were all significant at $\mathrm{p}<0.001$, whereas in dearomatised red wine, test matrices with higher than average concentrations of ethyl hexanoate, ethyl octanoate or ethyl 3-hydroxybutanoate were not recognised. Thus, the authors concluded that model wines do not provide a realistic scenario for threshold studies on wine. The argument for using de-aromatised red wine to study the aromatic impact of volatiles was supported. In fact, odour thresholds in any matrix other than the study matrix may be irrelevant, as suggested by Meilgaard et al. (2015). Ideally, a researcher should work out each individual ODT for each individual matrix, and stay in that specific matrix for the entire duration of a study. Data generated without establishing the ODT in the study matrix are meaningless, as the threshold of odour detection will be different in every cultivar and style. As Heymann (2018, personal communication) observed, "There is no way to make predictions about anything as it is all matrix dependent".

\section{The 'judge effect' (differences between panellists) in olfac- tory perception}

Another important issue affecting differences in the perception of odours in solution is that brought about by the 'judge effect'; i.e. differences between individuals in terms of their perceptual ability, experience and context.

Tempere et al. (2012) noted that studies have shown considerable variation in chemosensory human capacities. Sensitivity to odours varies among individuals, so panellists in a testing situation could assign different odour concentrations to the same sample (Brattoli et al., 2011). Not only does human olfactory perceptive ability differ enormously between individuals, but the hedonic response also varies. Keller et al. (2007) reported large perceptual variations in the intensity and pleasantness of androstenone, an odorous steroid. It was variously perceived by different individuals as offensive ('sweaty', 'urinous'), pleasant ('sweet', 'floral') or 'odourless'. In addition to their own physiology, many factors are known to affect panellists, including the time of day, illness (Brattoli et al., 2011), ambient temperature and odour, sensory fatigue (Ferdenzi et al., 2014), and the effects of other compounds present in the wine, such as alcohol (Goldner et al., 2009). Gender is also known to have an effect on the ability to detect odours, with women being recognised as generally more sensitive to a wider range of odours in wine (Wurz et al., 2017). Tempere et al. (2016) noted that even wine-tasting experts can show high olfactory detection thresholds for key compounds of wine, which is not ideal when wine quality depends on fault detection at low levels, and adapted training for professionals in the wine industry may be appropriate.

Several studies have shown that the perception of odour quality is shaped by experience and have illustrated that, in cross-cultural comparisons (Pangborn et al., 1988; Chrea et al., 2004; Wilson, 2005) and across a person's lifespan, physiological changes and experience may alter olfactory perception (Barkat et al., 2012). Well-known odours are usually rated as more pleasant, which suggests that humans prefer the smells they frequently experience (Distel et al., 1999), confirming the experience-dependency of odour quality judgments (Kaeppler \& Mueller, 2013). Thus, people at comparable ages, with similar cultural backgrounds and without physiological issues, may have similar olfactory perceptions. Experience has also been shown to influence quality perception by providing background to the identity, function or effect of an odour. Barkat et al. (2012) outlined that there seems to be conflicting evidence for whether experience and training could have an impact on olfactory processing and perception, but their study revealed differences in the perception of mixtures between naïve subjects and experts. These authors support the idea that olfactory expertise can modify the perception of a mixture and distinguish elements from the configuration. Expert subjects, however, are more accurate in identifying individual odours due to more sharply defined internal references as a result of exposure to odour reference standards (Barkat et al., 2012). It has been shown that training has a positive effect on the sensitivity of panellists for particular odours (Tempere et al., 2012, McKay et al., 2018), and that culturally acquired experience (for example, cooking specific foods), rather than perceptual processes in 
general, affects the evaluation of familiar versus unfamiliar odours (Ayabe-Kanamura et al., 1998). Panellists with the same level of experience tend to evaluate consistently, but experts use additional and specific descriptors to verbalise their perceptions (Lawless \& Heymann, 2010), which could be ascribed to enhanced perceptual skills (Parr et al., 2011). Training might enhance both perceptual and verbal skills, and enrich olfactory terminology. Laymen usually have major difficulties in naming even familiar odours correctly, and identification rates rarely exceed 50\% (Cain et al., 1998).

Odours are also powerful cues for autobiographical memories (Kaeppler \& Mueller, 2013). Thus, when people cannot identify an odour, they will associate it with places and situations ("the beach"), activities ("cleaning," "gardening"), effects ("peaceful"), or - on the most basic level - hedonic ratings ("nice" or "horrible"). Chrea et al. (2004) argued that odours are only arranged semantically when verbal or visual identifiers are available, so to facilitate satisfactory communication despite inadequacy of language, odour professionals have acquired cognitive categories and established professional terminologies (lexicons) that allow them to allocate odours to discrete conceptual categories. An example of this would be the 'aroma wheel' conceptualised by Noble et al. (1987). It is a matter of scientific debate whether odour categories are innate and thus universal, or learned. A mental representation of an odour, also called an "odour object" (Wilson \& Sullivan, 2011), will be shaped by various interactions between its characteristics and the impact of physiology, knowledge and culture. Unquestionably, the odour classes applied by odour professionals are acquired, with various findings indicating that experience yields odour arrangements that are different from the systems used by non-professionals, which include the "pleasantness" factor. When attribute lists devised by experts are used by laymen, terms are misunderstood and used differently by the untrained subjects (Lawless \& Heymann, 1998; Kaeppler \& Mueller, 2013). When sensory panellists agree on their perceptions in an 'alignment' exercise, this may still overrate or underemphasise certain quality aspects, depending on the study requirements, but this aspect of DA has not been researched very well. Different approaches to data analysis will also yield results that might not accurately reflect the perceptions of laymen when the data are interpreted by researchers or specialists, a qualitative data management issue that cross-cuts disciplines.

Elucidating meaningful links between even simple chemical structures and perceived odours from sensory data, the so-called SORs or 'structure-odour relationships' (Kaeppler \& Mueller, 2013) have not met with complete success. Modern computational approaches and access to thousands of physicochemical configurations and odour attributes have provided a few basic conclusions, but a lot of questions remain unanswered (Sell, 2006; De March et al., 2015; Keller et al., 2017). The olfactory perception space is acknowledged to be weak and 'highly dimensional' (Kaeppler \& Mueller, 2013), the nomenclature is often arbitrary, and odour classes overlap. The reliability of both perception and verbal expression is questionable, and olfactory perceptions are not necessarily stable over time (Wilson \& Sullivan, 2011). It is recognised that different people do not perceive identical odorants in the same way, and do not verbalise their olfactory perceptions consistently, but this has not been researched well. Questions also remain concerning the SORs of broad classes of molecules, the role of functional groups in the perception of odour, characterisation of single compounds at various levels, and the perception of odour interactions for simple and more complex mixtures.

\section{Interaction effects}

A much more complex aspect of wine aroma than the partitioning between gas and liquid phases is the perceptual interaction between various aromatic compounds, including synergistic (hyper-additive) effects (Lytra et al., 2012, 2013) and masking effects. Research has shown that aroma compounds in wine, such as thiols and terpenes, 'interact' (Atanasova et al., 2005b; Ferreira et al., 2016; Wilson et al., 2018) or, to be more precise, manifest different olfactory perceptual characteristics when compounds are present as mixtures in solution compared to solutions containing single compounds. In the case of wine, these perceptual effects are interpreted as changes to the aroma profile, which may lead to increased complexity, or to decreases in typicality of cultivar or style. It may be the case that certain compounds, while not present individually at sufficient intensity to cause a quality issue, can 'interact' when present in combination, leading to off-odours (Panzeri, 2013).

\section{The nature of olfactory perceptual interactions}

As most real-world odours are complex mixtures of distinct components, olfactory systems will adopt different strategies to deal with this complexity. In elemental processing, odour perception is derived from the sum of its parts; in configural processing, the parts are integrated into unique perceptual wholes (Howard \& Gottfried, 2014). Mammalian odour receptors $(\mathrm{OR})$ are able to detect and distinguish between thousands of odours in a combinatorial response to odorant molecules. A single aroma can elicit a response from multiple receptors, or a single receptor could respond to multiple odorants (Wilson \& Stevenson, 2006). An odorant may cause a unique combination of responses from several receptors, which endows the olfactory system with powerful discriminatory ability. The mechanisms by which the olfactory system functions are starting to be elucidated in physiological studies in insects like fruit flies (Christiaens et al., 2014) and mammals like mice (Haddad et al., 2010; Wilson \& Sullivan, 2011). Chemists have also been trying to link olfactory properties with chemical structures (Czerny et al., 2011; De March et al., 2015), and geneticists have been attempting to pinpoint genes associated with olfaction (Wooding, 2013; Sell, 2014). Different types of interactions can occur at the peripheral level, depending on the odorant concentration ratios, which affect a mixture's perceptual properties. Wilson and Stevenson (2006) hypothesised that perceptual-grouping and pattern-recognition abilities of the piriform cortex place an upper limit of three components on odour mixture analysis by humans. Beyond that limit, individual component analysis becomes faulty and odorant mixtures are processed as a 'single perceptual gestalt'. Although odorant mixture interactions can occur even with novel odorants, experience can shape cortical mixture 
processing. Also, when a mixture is familiar, cortical neurons treat the mixture as a unique object, different from its components, whereas without experience, cortical neurons treat mixtures and their components as more similar. Studies in olfactory perception have also shown the importance of peripheral interactions and past experience (Barkat et al., 2012) in the coding of complex odorant mixtures. Howard and Gottfried (2014) emphasise that the rules that govern the involvement of either elemental or configural processes during odour perception have been poorly investigated. There is also little understanding of peripheral coding of odorants' mixtures, even though the properties of individual components may be known (Thomas-Danguin et al., 2014). The physiological origin of olfactory interactions specific to wine has been addressed in very few studies (Chaput et al., 2012; Silva Teixeira et al., 2016), and there are still a great number of unexplained and unexplored issues concerning wine-related olfactory perception and learning.

One possible explanation for this lack of investigation, especially in humans, could be the difficulty quantifying odour quality (Barkat et al., 2012) - for the reasons given in Section 4 above. Barkat et al. (2012) noted that the choice of sensory method is a critical step in investigating blending processes in odour mixtures. This is especially important when perceptual odour blending and interactions may affect the mixture's odour quality. These authors recommend that a detailed aroma-profiling task involving both singlecomponent descriptors and a main character descriptor should be undertaken if odour blends are to be described. However, a limitation of such a procedure would be that the panellists are engaged in an analytical perception-processing strategy, which could decrease synthetic processing and consequently the blending effect (Le Berre et al., 2008). Aroma-profiling tasks that require odour references for each descriptor, presented at the beginning of panel sessions, might also modulate the later perception and evaluation of blending mixtures (Barkat et al., 2012).

The perception of odour mixtures, such as those present in wine, is far more complicated due to interactions arising from the complex chemical signal-encoding and processing within the olfactory system (Thomas-Danguin et al., 2014). The variety of sensory perceptions observed when presented with mixtures of odorants could be the result of both qualitative (odour quality) and quantitative (odour intensity) perceptual interactions between odorants (Laing et al., 1984, 1994). The theory of 'odour-object' encoding underpins the neurophysiological processes involved in extracting only relevant information from complex chemical mixtures in the environment (Wilson \& Sullivan, 2011; Thomas-Danguin et al., 2014). Interactions occurring at the peripheral level of the olfactory system play an important role in processing odorant mixtures and triggering the coding (Laing et al., 1984). Initially, odorants are sampled by a large number of ORs located in the cilia of olfactory sensory neurons/ cells (OSNs). Each OSN/OR usually responds to a variety of odorants so that the identity of a molecule is encoded by the combination of ORs/OSNs that recognise it (ThomasDanguin et al., 2014). The overlapping response profiles of OSNs, and the subsequent encoding, are under cognitive control, and learning will shape perceptions and continued exposure will lead to the experience of mixtures as odour objects or specific odour configurations (Thomas-Danguin et al., 2014). An efficient memory-based olfactory system would learn which features should be grouped (associated) together to form a single olfactory odour object (e.g. 'smoke'), despite the fact that this odour is composed of hundreds of components (Wilson, 2005), and very complex stimuli would be simplified, vastly extending the tuning range of the olfactory system. The perceptual configuration of mixtures into simpler odour objects would thus improve an organism's ability to extract information from the environment (Wilson \& Stevenson, 2006), and cognitive processes should decrease the chemical complexity of the environment by building experience-dependent perceptual associations (Wilson \& Stevenson, 2006).

Studies in different species have compared the responses of OSNs to binary mixtures and their components (ThomasDanguin et al., 2014), and data modelling (Münch et al., 2013) suggests that both competitive and non-competitive interactions occur at the receptor level. Thomas-Danguin et al. (2014) note that there is competitive interaction when two molecules bind to the same receptor binding site, which might involve agonist (molecules that activate the receptor) odorants, or agonist/antagonist (a molecule that binds to the receptor but is unable to activate it) competition. It appears that three types of interactions have been observed, depending on the nature of the odorants included and the concentration ratios. In the first (and most typical) case, the response intensity of OSNs to the mixture is lower than the response to the most intense component (subtraction or hypo-addition). There seems to be some incongruence in the literature regarding the perception of iso-intense mixtures. Laing et al. (1984) observed that, in binary mixtures, both odorants were perceived only when they were similar in intensity. Wilson and Stevenson (2006) noted that mixing two odorants that are perceptually similar may have the effect of doubling the concentration of one odorant, and Atanasova et al. (2005a) found that predictive models for odour intensity and quality perception were unable to account for the odour quality dominance in mixtures with iso-intense components. Effects are also difficult to predict if concentrations are dissimilar. Chaput et al. (2012) showed competitive interaction in wine between whiskey lactone and isoamyl acetate, with the perception of 'fruity notes' of a mixture increased by low concentrations of whiskey lactone and decreased by high concentrations. Barkat et al. (2012) noted that odorant combinations of two or three components are more inclined to elicit perceptual interactions, with configural processing conferring a modification in odour quality. Specific training and exposure to odours experienced by experts cause their olfactory systems to engage more readily in the elemental processing of odour mixtures, and thus they have the ability to better 'select out' individual components from odour mixtures. This does not seem to have been tested well in the literature.

Olfactory interaction in red wine matrices: previous findings

Pineau et al. (2009) demonstrated that, in mixtures of dearomatised red wine, very small variations were perceived in 
the concentrations of some ethyl esters, even at concentrations far below their individual olfactory thresholds, and this affected 'red berry' and 'blackberry' aromas. Lytra et al. (2012) used omission tests to show that ethyl 2-hydroxy4-methylpentanoate was responsible for enhancing 'blackberry' and 'fresh fruit' aromas. These workers also established that a combination of diacetyl, acetoin, acetic acid and $\gamma$-butyrolactone, at levels between $2 \%$ and $40 \%$ of their perception thresholds, had hypo-additive or synergistic effects on the 'fresh fruity' aroma of red wine. Lytra et al. (2013) also showed that ethyl-3-hydroxybutanoate and 2-methylpropylacetate in model wine mixtures led to a significant decrease in the olfactory threshold of the 'fruity' aroma pool, demonstrating a synergistic effect in increasing the overall intensity. The authors concluded that compounds with similar chemical structures participated in modulating fruity aromas, specifically the 'berry' and 'fresh fruit' aromas. Ferreira et al. (2002) observed an additive effect between furaneol and homofuraneol in reconstitution studies in red wines. In a larger study, Ferreira et al. (2016) noted that individual compounds in de-aromatised red wine explained only $15 \%$ of the sensory effects. Norisoprenoids ( $\beta$-damascenone and $\alpha$-ionone) were observed to influence the perception of 'dried' and 'black fruits' and suppress 'red fruits'. Branched acids (2- methylpropanoic acid and 2- and 3-methyl butyric acid) were shown to suppress 'black fruit' aroma and enhance 'red' and 'dried fruits'. Strong suppressors of 'red fruit' attributes and 'woody' notes included 2- and 3- methyl propanol. These examples emphasise the effect of perceptual interactions on the intensity and quality of fruity aromas in the wine, but do not characterise any new 'odour object' formation as a result of perceptual interactions of the compounds.

Recent efforts to investigate volatile phenol (VP)related off-flavours have been concentrated on smokerelated attributes, and a number of studies have an analytical focus. It has been established that VPs can be detrimental to wine quality at low levels (Panzeri, 2013). Descriptors of various VPs spiked into wine were established during the training sessions in this study and ranged from 'tar-like' and 'chemical' for the cresols, to 'sick sweet' and 'medicinal' for the xylenols (Panzeri, 2013). Descriptive analysis was also used to characterise interactions between phenol, $O$-cresol, 3,4- xylenol and 4-EP at low levels. Descriptors included 'smoky-ash', 'medicinal/ Band-aid', 'burnt rubber' and 'sick-sweet'. Interestingly, in this study, phenol itself in red wine was described as 'floral' and 'sweet', enhancing the berry jam character of the Pinotage base wine. Other studies looking at the interactions between VPs or with other taint compounds are scarce. Lorrain et al. (2013) and Tempere et al. (2016) investigated the masking effects of ethylphenols on fruity odours. In one of the few studies conducted on the effect of TCA in wine, Tempere et al. (2017) investigated the masking effect of subthreshold concentrations of TCA on a range of aromatic notes. They showed that TCA caused 'counteraction of odorant specificity', or that low levels made other odours more difficult to identify. Tempere et al.'s results suggest that the TCA interaction takes place at the receptor level, and their study provides experimental confirmation of the widespread idea that constituents in non- perceptible concentrations influence the perceived quality of mixtures of odorous compounds.

Even with a compound as well known as IBMP for its anecdotal masking (antagonistic/'scalping') effect, studies in red wine are surprisingly scarce. Van Wyngaard et al. (2014) investigated the interaction between IBMP and 3-mercaptohexan-1-ol (3MH) in de-aromatised Sauvignon blanc wine and found that IBMP suppressed the tropical attributes associated with $3 \mathrm{MH}$, and that $3 \mathrm{MH}$ suppressed the green attributes that correlated with IBMP. The concentrations at which the suppression occurred and the degree of suppression were different for each attribute. Other than Lapalus's (2016) study quantifying and characterising IBMP in Cabernet Sauvignon, studies on its effect and interactions in wine are rare in the primary literature.

\section{CONCLUSIONS}

Perceptive interaction phenomena between aroma compounds in red wines represent an important source of complexity, and emphasise the importance of the matrix and the need to consider other compounds in solution when carrying out sensory studies. This area warrants a lot more attention from oenology researchers, particularly in the arena of off-odours and taints, as there are few studies that help to elucidate the effects of important contributors.

Despite the importance of wine quality for consumers, and the increasing sensitivity and availability of chemical methods for testing for contributing compounds, there are surprisingly few formal studies quantifying or qualifying off-flavours. A lot of the existing information is anecdotal. The studies that have been carried out are centred on more obvious and easily perceived wine flaws, neglecting faults that do not present a simple, easily recognisable profile. Examples of faults that have still not been addressed include 'chemical-related', 'vegetal-related', 'burnt rubber/acrid', and 'animal-related' faults. There is also a scarcity of studies in the area of 'green' and 'herbaceous' off-flavours in wine that cannot be explained by compositional data, especially those that may be related to the additive or subtractive effects of interactions. A number of authors have emphasised the need to understand the 'green' off-flavours in wine, and to carry out studies in this area.

Although the effects of the compounds most frequently associated with smoke taint in wine (guaiacol and 4-methyl guaiacol) have been well described, the effects of certain volatile phenols (VPs) that are known to be produced during smoke events (for example the xylenols) have not yet been well documented in wine. Little information exists on the majority of the alkylated volatile phenols in wine, despite these compounds having strong odours and being present in wine as a result of smoke taint or other contamination. Despite comprehensive studies of many aspects of VPs in smoke taint, particularly by Australian researchers, most VPs have not been characterised formally in any wine matrix or assigned threshold values on the basis of a formal determination study. Even within a broad category (white or red), the wine style and choice of cultivar may alter detection thresholds, but evidence from formal studies looking at this aspect is hard to find. Even something as obvious as $\% \mathrm{v} / \mathrm{v}$ alcohol can affect the perception of 
thresholds of odour compounds, but surprisingly few studies exist that have examined this aspect in wine. This may be the result of interactions of low levels of compounds across different chemical groups, but a significant gap exists in the literature in this regard, specifically at levels below the detection threshold. Interactions between VPs themselves are an area that requires attention, as well as whether VPs could contribute to other issues like herbaceousness through interactions with compounds that include IBMP and TCA. The effect of wine matrices on the ODTs for VPs, IBMP and TCA has received little attention in the primary literature. The ODTs of less common VPs may also have important sensory effects (e.g. phenol and xylenols) in red wine, but there has been little research on this. Although rapid sensory methodologies have received attention in the primary and popular wine literature, there is still a lot of work needed to fully describe the applicability of particular methods to various evaluation scenarios in wine tasting.

On a more fundamental level, elucidating meaningful links between even simple chemical structures and perceived odours from sensory data, the so-called 'structure-odour relationships', is still not well-documented, even for simple aromatic compounds. Studies on the role of functional groups in the perception of odour, the characterisation of single compounds at various levels and the perception of odour interactions in wine are lacking. Modern computational approaches and access to thousands of physicochemical configurations and odour attributes have provided some knowledge, but a lot of questions remain unanswered. The olfactory perception space is nebulous, the nomenclature is arbitrary, and odour classes are overlapping, complex and confusing.

\section{LITERATURE CITED}

Alberts, P., Kidd, M., Stander, M.A., Nieuwoudt, H.H., Tredoux, A.G.J. \& De Villiers, A., 2013. Quantitative survey of 3-alkyl-2-methoxypyrazines and first confirmation of 3-ethyl-2-methoxypyrazine in South African Sauvignon blanc wines. S. Afr. J. Enol. Vitic. 34(1), 54-67.

Allen, M., Lacey, M. \& Boyd, S., 1996. Existence of different origins for methoxypyrazines of grapes and wines. In: Takeoka, G.R., Teranishi, R., Williams, P.J. \& Kobayashi, A. (eds). Biotechnology for Improved Foods and Flavors. American Chemical Society, Washington DC, pp. 220 - 227.

Álvarez-Rodríguez, M.L., López-Ocaña, L., López-Coronado, J.M., Rodríguez, E., Martínez, M.J., Larriba, G. \& Coque, J.J.R., 2002. Cork taint of wines: Role of the filamentous fungi isolated from cork in the formation of 2,4,6-trichloroanisole by $\mathrm{O}$ methylation of 2,4,6-trichlorophenol. Appl. Environ. Microbiol. 68(12), 5860-5869.

Atanasova, B., Thomas-Danguin, T., Chabanet, C., Langlois, D., Nicklaus, S. \& Etievant, P., 2005a. Perceptual interactions in odour mixtures: Odour quality in binary mixtures of woody and fruity wine odorants. Chem. Senses 30(3), 209-217.

Atanasova, B., Thomas-Danguin, T., Langlois, D., Nicklaus, S., Chabanet, C. \& Etiévant, P., 2005b. Perception of wine fruity and woody notes: Influence of peri-threshold odorants. Food Qual. Pref. 16(6), 504-510.

Audouin, V., Bonnet, F., Vickers, Z.M. \& Reineccius, G.A., 2001. Limitations in the use of odor activity values to determine important odorants in foods. ACS Symposium Series 782, 156-171.
Barkat, S., Le Berre, E., Coureaud, G., Sicard, G. \& Thomas-Danguin, T., 2012. Perceptual blending in odor mixtures depends on the nature of odorants and human olfactory expertise. Chem. Senses 37(2), 159-166.

Bearak, B., 2009 (28 June). A whiff of controversy and South African wines. The New York Times. Online: https:/www.nytimes.com/2009/06/29/world/ africa/29stellenbosch.html [accessed 12 November 2019].

Boidron, J., Chatonnet, P. \& Pons, M., 1988. Influence du bois sur certaines substances odorantes des vins. J. Int. Sci. Vigne Vin 22(4), 275-294.

Botha, J., 2010. Sensory, chemical and consumer analysis of Brettanomyces spoilage in South African wines. Master's thesis, Stellenbosch University, Private Bag X1, 7602 Matieland (Stellenbosch), South Africa.

Brattoli, M., De Gennaro, G., De Pinto, V., Loiotile, A., Lovascio, S. \& Penza, M., 2011. Odour detection methods: Olfactometry and chemical sensors. Sensors (Basel) 11(5), 5290-5322.

Buser, H.R., Zanier, C. \& Tanner, H., 1982. Identification of 2,4,6-trichloroanisole as a potent compound causing cork taint in wine. J. Agric. Food Chem. 30(2), 359-362

Cadahía, E., Fernández de Simón, B. \& Jalocha, J., 2003. Volatile compounds in Spanish, French, and American oak woods after natural seasoning and toasting. J. Agric. Food Chem. 51(20), 5923-5932.

Cain, W.S., De Wijk, R., Lulejian, C., Schiet, F. \& See, L.C., 1998. Odor identification: Perceptual and semantic dimensions. Chem. Senses 23, 309326.

Cameleyre, M., Lytra, G., Tempere, S. \& Barbe, J.C., 2018. Perceptive interactions in red wines: How physico-chemical pre-sensorial effects may affect red wine fruity aromatic expression? In: Siegmund, B. \& Letner, E. (eds). Flavour Science. Proceedings of the XV Weurman Flavour Research Symposium. Technischen Universitate Graz, Graz, Germany. pp. 241 - 244.

Chaput, M.A., El Mountassir, F., Atanasova, B., Thomas-Danguin, T., Le Bon, A.M., Perrut, A. \& Duchamp-Viret, P., 2012. Interactions of odorants with olfactory receptors and receptor neurons match the perceptual dynamics observed for woody and fruity odorant mixtures. Eur J. Neurosci. 35(4), 584-597.

Chatonnet, P., Dubourdie, D., Boidron, J. \& Pons, M., 1992. The origin of ethylphenols in wines. J. Sci. Food. Agric. 60(2), 165-178.

Chrea, C., Valentin, D., Sulmont-Ross, C., Ly Mai, H., Hoang Nguyen, D. \& Abdi, H., 2004. Culture and odor categorization: Agreement between cultures depends upon the odors. Food Qual. Prefer. 15(7-8), 669-679.

Christiaens, J.F., Franco, L.M., Cools, T.L., De Meester, L., Michiels, J., Wenseleers, T. \& Verstrepen, K.J., 2014. The fungal aroma gene ATF1 promotes dispersal of yeast cells through insect vectors. Cell Rep. 9(2), 425-432.

Cravero, M.C., Bonello, F., Del Pazo Alvarez, M., Tsolakis, C. \& Borsa, D., 2015. The sensory evaluation of 2,4,6-trichloroanisole in wines. J. Inst. Brewing 121, 411-417.

Culleré, L., Cacho, J. \& Ferreira, V., 2007. An assessment of the role played by some oxidation-related aldehydes in wine aroma. J. Agric. Food Chem. 55(3), 876-881.

Curtin, C., Bramley, B., Cowey, G., Holdstock, M., Lattey, K., Coulter, A., Henschke, P., Francis, L. \& Godden, P., 2008. Sensory perception of Brett and relationship to consumer preference. In: Blair, I. \& Pretorius, R.J. (eds). Proc. $13^{\text {th }}$ Aust. Wine Ind. Tech. Conf., Adelaide, Australia. pp. $207-211$.

Czerny, M., Brueckner, R., Kirchhoff, E., Schmitt, R. \& Buettner, A., 2011. The influence of molecular structure on odor qualities and odor detection thresholds of volatile alkylated phenols. Chem. Senses 36(6), 539-553.

Ayabe-Kanamura, S., Saito, S., Distel, H., Martínez-Gómez, M. \& Hudson, R., 1998. Differences and similarities in the perception of everyday odors. A Japanese-German cross-cultural study. Chem. Senses 23(1), 31-38. 
Czerny, M., Christlbauer, M., Fischer, A., Granvogl, M., Hammer, M. \& Schieberle, P., 2008. Re-investigation on odour thresholds of key food aroma compounds and development of an aroma language based on odour qualities of defined aqueous odorant solutions. Eur. Food Res. Tech. $228(20), 265-273$.

De March, C.A., Ryu, S.E., Sicard, G., Moon, C. \& Golebiowski, J., 2015. Structure-odour relationships reviewed in the postgenomic era. Flav. Frag. J. 30(5), 342-361

De Vries, C.J., Buica, A., Brand, J. \& Mckay, M., 2016. The impact of smoke from vegetation fires on sensory characteristics of Cabernet Sauvignon wines made from affected grapes. S. Afr. J. Enol. Vitic. 37(1), 22-30.

Distel, H., Ayabe-Kanamura, S., Martinez-Gomez, M., Schiker, I., Kobayakawa, T. \& Saito, S., 1999. Perception of everyday odors Correlation between intensity familiarity and strength of hedonic judgment. Chem. Senses 24, 191-199.

Eisele, T.A. \& Semon, M.J., 2006. Best estimated aroma and taste detection threshold for guaiacol in water and apple juice. J. Food Sci. 70(4), S267-S269.

Escudero, A., Campo, E., Fariña, L., Cacho, J. \& Ferreira, V., 2007. Analytical characterization of the aroma of five premium red wines. Insights into the role of odor families and the concept of fruitiness of wines. J. Agric. Food Chem. 55(110), 4501-4510.

Etievant, P.X., 1981. Volatile phenol determination in wine. J. Agric. Food Chem. 29(1), 65-67.

Ferdenzi, C., Poncelet, J., Rouby, C. \& Bensafi, M., 2014. Repeated exposure to odors induces affective habituation of perception and sniffing. Front. Behav. Neurosci. 8, Art. 119. doi:10.3389/fnbeh.2014.00119

Fernández de Simón, B., Cadahia, E., Sanz, M., Poveda, P., Perez-Magarin, S., Ortega-Heras, M. \& Gonzalez-Huerta, C., 2008. Volatile compounds and sensorial characterization of wines from four Spanish denominations of origin, aged in Spanish Rebollo (Quercus pyrenaica Willd.) oak wood barrels. J. Agric. Food Chem. 56, 9046-9055.

Ferreira, V., 2012. Revisiting psychophysical work on the quantitative and qualitative odour properties of simple odour mixtures: A flavour chemistry view. Part 2: Qualitative aspects. A review. Flavour Fragr. J. 27(3), 201-215.

Ferreira, V., Ortín, N., Escudero, A., Lopez, R. \& Cacho, J., 2002. Chemical characterization of the aroma of Grenache rosé wines: Aroma extract dilution analysis, quantitative determination, and sensory reconstitution studies. J. Agric. Food Chem. 50(14), 4048-4054

Ferreira, V., Sáenz-Navajas, M.P., Campo, E., Herrero, P., De la Fuente, A. \& Fernández-Zurbano, P., 2016. Sensory interactions between six common aroma vectors explain four main red wine aroma nuances. Food Chem. 199, $447-456$

Francis, I. \& Newton, J., 2005. Determining wine aroma from compositional data. Aus. J. Grape Wine Res. 11(2), 114-126.

Franco-Luesma, E. \& Ferreira, V., 2016. Reductive off-odors in wines: Formation and release of $\mathrm{H}_{2} \mathrm{~S}$ and methanethiol during the accelerated anoxic storage of wines. Food Chem. 199, 42-50.

Fried, J.S., Torn, M.S. \& Mills, E., 2004. The impact of climate change on wildfire severity: A regional forecast for northern California. Clim. Change 64(1/2), 164-191.

Fudge, A.L., Ristic, R., Wollan, D. \& Wilkinson, K.L., 2011. Amelioration of smoke taint in wine by reverse osmosis and solid phase adsorption. Aus. J. Grape. Wine Res. 17(2), 41-48.

Fugelsang, K.C. \& Edwards, C.G., 2007. Wine Microbiology. Practical Applications and Procedures. Springer Science+Business Media, New York, NY.
Goldammer, J., Statheropoulos, M. \& Andreae, M., 2009. Impacts of vegetation fire emissions on the environment, human health, and security: A global perspective. Dev. Env. Sci. 8, 3-36.

Goldner, M., Zamora, M., De Leo Lira, P., Gianninoto, H. \& Bandoni, A., 2009. Effect of ethanol level in the perception of aroma attributes and the detection of volatile compounds in red wine. J. Sens. Stud. 24(2), 243-257.

Goode, J., 2008. Burnt rubber: The great South African wine debate. Online: https://wineanorak.com/blog/2008/10/burnt-rubber-great-south-africanwine.html [accessed 21 November 2019].

Griffiths, N.M., 1974. Sensory properties of the chloro-anisoles. Chem Senses 1(2), 187-195.

Haddad, R., Weiss, T., Khan, R., Nadler, B., Mandairon, N., Bensafi, M., Schneidman, E. \& Sobel, N., 2010. Global features of neural activity in the olfactory system form a parallel code that predicts olfactory behavior and perception. J. Neurosci. 30(27), 9017-9026.

Hammond, C.E., 2015. South African wine under fire. Online: http://www carolynevanshammond.com/blog/2015/10/12/south-african-wine-underfire-1 [accessed 21 November 2019].

Hayasaka, Y., Baldock, G.A., Parker, M., Pardon, K. H., Black, C.A., Herderich, M.J. \& Jeffery, D.W., 2010. Glycosylation of smoke-derived volatile phenols in grapes as a consequence of grapevine exposure to bushfire smoke. J. Agric. Food Chem. 58(20), 10989-10998.

He, J., Zhou, Q., Peck, J., Soles, R. \& Qian, M.C., 2013. The effect of wine closures on volatile sulfur and other compounds during post-bottle ageing. Flavour Frag. J. 28(2), 118-128.

Hein, K., Ebeler, S. \& Heymann, H., 2009. Perception of fruity and vegetative aromas in red wine. J. Sens. Stud. 24(3), 441-455.

Heyns, E., 2014. The green South African palate - When does mint become eucalyptus or even downright weedy? Wineland Magazine. Online: https:// www.wineland.co.za/the-green-south-african-palate-when-does-mintbecome-eucalyptus-or-even-downright-weedy/ [accessed 21 November 2019].

Howard, J.D. \& Gottfried, J.A., 2014. Configural and elemental coding of natural odor mixture components in the human brain. Neuron 84(4), 857869.

International Standards Organisation (ISO), 2002. ISO 13301 Sensory analysis-Methodology-General guidance for measuring odour, flavour and taste detection thresholds by a three-alternative forced-choice (3-AFC) procedure. International Standards Organisation, Geneva, Switzerland.

Jackson, R.S., 2014 (4 ${ }^{\text {th }}$ ed). Sensory perception and wine assessment: Chapter 11. Wine Science. Academic Press, Cambridge, Massachusetts, USA. pp. $831-888$.

Kaeppler, K. \& Mueller, F., 2013. Odor classification: A review of factors influencing perception-based odor arrangements. Chem. Senses 38(3), 189209.

Keller, A., Gerkin, R.C., Guan, Y., Dhurandhar, A., Turu, G., Szalai, B. $\&$ Meyer, P., 2017. Predicting human olfactory perception from chemical features of odor molecules. Science 355(6327), 820-826.

Keller, A., Zhuang, H., Chi, Q., Vosshall, L.B. \& Matsunami, H., 2007. Genetic variation in a human odorant receptor alters odour perception [Letter]. Nature 449, 468-472.

Kelly, D. \& Zerihun, A., 2015. The effect of phenol composition on the sensory profile of smoke affected wines. Molecules 20(6), 9536-9549.

Kelly, D., Zerihun, A., Hayasaka, Y. \& Gibberd, M., 2014. Winemaking practice affects the extraction of smoke-borne phenols from grapes into wines. Aus. J. Grape Wine Res. 20(3), 386-393. 
Kelly, D., Zerihun, A., Singh, D.P., Vitzthum von Eckstaedt, C., Gibberd, M., Grice, K. \& Downey, M., 2012. Exposure of grapes to smoke of vegetation with varying lignin composition and accretion of lignin derived putative smoke taint compounds in wine. Food Chem. 135(2), 787-798.

Kennison, K.R., Wilkinson, K.L., Pollnitz, A.P., Williams, H.G. \& Gibberd, M.R., 2009. Effect of timing and duration of grapevine exposure to smoke on the composition and sensory properties of wine. Aus. J. Grape Wine Res. $15,228-237$.

Kennison, K.R., Wilkinson, K.L., Pollnitz, A.P., Williams, H.G. \& Gibberd, M.R., 2011. Effect of smoke application to field-grown Merlot grapevines at key phenological growth stages on wine sensory and chemical properties. Aus. J. Grape Wine Res. 17(2), S5-S12.

Kennison, K.R., Wilkinson, K.L., Williams, H.G., Smith, J.H. \& Gibberd, M.R., 2008. Smoke-derived taint in wine: Effect of postharvest smoke exposure of grapes on the chemical composition and sensory characteristics of wine. J. Agric. Food Chem. 55(26), 10897-10901.

Krstic, M.P., Johnson, D.L. \& Herderich, M.J., 2015. Review of smoke taint in wine: Smoke-derived volatile phenols and their glycosidic metabolites in grapes and vines as biomarkers for smoke exposure and their role in the sensory perception of smoke taint. Aus. J. Grape. Wine Res. 21, 537-553.

Laing, D.G., Eddy, A. \& Best, J.D., 1994. Perceptual characteristics of binary, trinary, and quaternary odor mixtures consisting of unpleasant constituents. Physiol. Behav. 56(1), 81-93.

Laing, D.G., Panhuber, H., Willcox, M.E. \& Pittman, E.A., 1984. Quality and intensity of binary odor mixtures. Physiol. Behav. 33(2), 309-319.

Lapalus, E., 2016. Linking sensory attributes to selected aroma compounds in South African Cabernet Sauvignon wines. Master's thesis, Stellenbosch University, Private Bag X1, 7602 Matieland (Stellenbosch), South Africa.

Lawless, H. \& Heymann, H., 1998 ( $2^{\text {nd }}$ ed). Sensory Evaluation of Food Principles and Practices. Springer, New York.

Lawless, H. \& Heymann, H., 2010 ( $2^{\text {nd }}$ ed). Measurement of Sensory Thresholds. Springer Science \& Business Media (Food Science Text Series), New York.

Le Barbé, E., 2003. Creating and validating an aroma and flavor lexicon for the evaluation of sparkling wines. Master's thesis, University of California, Davis, California, USA.

Le Berre, E., Thomas-Danguin, T., Béno, N., Coureaud, G., Etiévant, P. \& Prescott, J., 2008. Perceptual processing strategy and exposure influence the perception of odor mixtures. Chem. Senses 33(2), 193-199.

Lorrain, B., Tempere, S., Iturmendi, N., Moine, V., De Revel, G. \& Teissedre, P.-L., 2013. Influence of phenolic compounds on the sensorial perception and volatility of red wine esters in model solution: An insight at the molecular level. Food Chem. 140(1-2), 76-82.

Lytra, G., Tempere, S., De Revel, G. \& Barbe, J.C., 2012. Impact of perceptive interactions on red wine fruity aroma. J. Agric. Food Chem. 60(50), 12260-12269.

Lytra, G., Tempere, S., Le Floch, A., De Revel, G. \& Barbe, J.C., 2013. Study of sensory interactions among red wine fruity esters in a model solution. J. Agric. Food Chem. 61(36), 8504-8513.

Malfeito-Ferreira, M., Barata, A. \& Loureiro, V., 2009. Wine spoilage by fungal metabolites. In: Moreno-Arribas, M.V. \& Polo, M.C. (eds). Wine Chemistry and Biochemistry. New York, NY: Springer Science+Business Media. pp. $615-645$.

Marais, J. \& Swart, E., 1999. Sensory impact of 2-methoxy-3isobutylpyrazine and 4-mercepto-4-methylpentan-2-one added to a neutral Sauvignon blanc wine. S. Afr. J. Enol. Vitic. 20, 77-79.

Martineau, B., Acree, T.E. \& Henick-Kling, T., 1995. Effect of wine type on the detection threshold for diacetyl. Food Res. Int. 28(2), 139-143.
Mazzoleni, V. \& Maggi, L., 2007. Effect of wine style on the perception of 2,4,6-trichloroanisole, a compound related to cork taint in wine. Food Res. Int. 40(6), 694-699

McKay, M., Bauer, F., Panzeri, V. \& Buica, A., 2018. Testing the sensitivity of potential panelists for wine taint compounds using a simplified sensory strategy. Foods 7(11), 176. doi:10.3390/foods7110176

Meilgaard, M.C., Carr, Th. \& Civille, G., 2015 (5 $5^{\text {th }}$ ed). Sensory evaluation techniques. CRC Press, Taylor \& Francis Group, New York.

Morrison, G.R., 1982. Measurement of flavour thresholds. J. Inst. Brew. $88,170-174$.

Mozzon, M., Savini, S., Boselli, E. \& Thorngate, J.H., 2016. The herbaceous character of wines. Ital. J. Food Sci. 28(2), 190-207.

Münch, D., Schmeichel, B., Silbering, A.F. \& Galizia, C.G., 2013. Weaker ligands can dominate an odor blend due to syntopic interactions. Chem. Senses 38(4), 293-304

Noble, A.C., Arnold, R.A., Buechsenstein, J., Leach, E.J., Schmidt, J.O. \& Stern, P.M., 1987. Modification of a standardized system of wine aroma terminology. Am. J. Enol. Vitic. 38(2), 143-146.

Noestheden, M., Thiessen, K., Dennis, E.G., Tiet, B. \& Zandberg, W.F., 2018. Quantitating organoleptic volatile phenols in smoke-exposed Vitis vinifera berries. J. Agric. Food Chem. 65(38), 8418-8425.

Oelofse, A., Lonvaud-Funel, A. \& Du Toit, M., 2009. Molecular identification of Brettanomyces bruxellensis strains isolated from red wines and volatile phenol production. Food Microbiol. 26(4), 377-385. https://doi. org/10.1016/j.fm.2008.10.011

Pagès, J., 2005. Collection and analysis of perceived product inter-distances using multiple factor analysis: Application to the study of 10 white wines from the Loire Valley. Food Qual. Pref. 16(7), 642-649.

Pangborn, R.M., Guinard, J.-X. \& Davis, R.G., 1988. Regional aroma preferences. Food Qual. Prefer. 1(1), 11-19.

Panzeri, V., 2013. Influence of vineyard posts type on the chemical and sensorial composition of Sauvignon blanc and Merlot wines. Master's thesis, Stellenbosch University, Private Bag X1, 7602 Matieland (Stellenbosch), South Africa.

Parker, B., Baldock, G., Haysaka, Y., Mayr, C., Williamson, P., Francis, I.L., Krstic, M., Herderich, M. \& Johnson, D., 2013. Seeing through smoke. Wine and Viticult. J. 28, 42-46.

Parker, M., Osidacz, P., Baldock, G.A., Hayasaka, Y., Black, C.A., Pardon, K.H. \& Francis, I.L., 2012. Contribution of several volatile phenols and their glycoconjugates to smoke-related sensory properties of red wine. J. Agric. Food Chem. 60(10), 2629-2637.

Parr, W.V., Mouret, M., Blackmore, S., Pelquest-Hunt, T. \& Urdapilleta, I., 2011. Representation of complexity in wine: Influence of expertise. Food Qual. Pref. 22(7), 647-660.

Parr, W.V., Green, J.A., White, K.G. \& Sherlock, R.R., 2007. The distinctive flavour of New Zealand Sauvignon blanc: Sensory characterisation by wine professionals. Food Qual. Pref. 18, 849-861.

Perrone, M.G., Carbone, C., Faedo, D., Ferrero, L., Maggioni, A., Sangiorgi, G. \& Bolzacchini, E., 2014. Exhaust emissions of polycyclic aromatic hydrocarbons, n-alkanes and phenols from vehicles coming within different European classes. Atmos. Environ. 82, 391-400.

Perry, D.M. \& Hayes, J.E., 2016. Effects of matrix composition on detection threshold estimates for methyl anthranilate and 2-aminoacetophenone. Foods 5(2), 35-45. https://doi.org/10.3390/foods5020035 
Petrozziello, M., Asproudi, A., Guaita, M., Borsa, D., Motta, S., Panero, L. \& Bosso, A., 2014. Influence of the matrix composition on the volatility and sensory perception of 4-ethylphenol and 4-ethylguaiacol in model wine solutions. Food Chem. 149, 197-202. https://doi.org/10.1016/j. foodchem.2013.10.098

Pineau, B., Barbe, J.C., Van Leeuwen, C. \& Dubourdieu, D., 2009. Examples of perceptive interactions involved in specific "Red-" and "Black-berry" aromas in red wines. J. Agric. Food Chem. 57(9), 3702-3708. https://doi. org/10.1021/jf803325y

Pollnitz, A.P., Pardon, K.H. \& Sefton, M.A., 2000. Quantitative analysis of 4-ethylphenol and 4-ethylguaiacol in red wine. J. Chrom. A 874, 101-109

Pollnitz, A.P., Pardon, K.H., Liacopoulos, D., Skouroumounis, G.K \& Sefton, M.A., 1996. The analysis of 2,4,6-trichloroanisole and other chloroanisoles in tainted wines and corks. Aus. J. Grape Wine Res. 2(3), 184-190.

Pollnitz, A.P., Pardon, K.H., Sykes, M. \& Sefton, M.A., 2004. The effects of sample preparation and gas chromatograph injection techniques on the accuracy of measuring guaiacol, 4-methylguaiacol and other volatile oak compounds in oak extracts by stable isotope dilution analyses. J. Agric. Food Chem. 52(11), 3244-3252.

Prescott, J., Norris, L., Kunst, M. \& Kim, S., 2005. Estimating a "consumer rejection threshold" for cork taint in white wine. Food Qual. Pref. 16(4), 345-349.

Prida, A. \& Chatonnet, P., 2010. Impact of oak-derived compounds on the olfactory perception of barrel-aged wines. Am. J. Enol. Vitic. 50(4), 447455

Rauhut, D. \& Kiene, F., 2019. Chapter 19: Aromatic compounds in red varieties. In: Red Wine Technology. Editors: Antonio Morata, Academic Press, Cambridge, Massachusetts, USA. pp, 273 - 282.

Ristic R., Boss, P. \& Wilkinson, K., 2015. Influence of fruit maturity at harvest on the intensity of smoke taint in wine. Molecules 20(5), 8913-8927.

Ristic, R., Van der Hulst, L., Capone, D.L. \& Wilkinson, K.L., 2017. Impact of bottle aging on smoke-tainted wines from different grape cultivars. J. Agric. Food Chem. 65(20), 4146-4152.

Robinson, A., Ebeler, S., Heymann, H., Boss, P., Solomon, P. \& Trengove, R., 2009. Interactions between wine volatile compounds and grape and wine matrix components influence aroma compound headspace partitioning. J. Agric. Food Chem. 57, 21, 10313-10322.

Romano, A., Perello, M.C., Lonvaud-Funel, A., Sicard, G. \& De Revel, G., 2009. Sensory and analytical re-evaluation of "Brett character". Food Chem. 114(1), 15-19.

Roujou de Boubee, D., Van Leeuwen, C. \& Dubourdieu, D., 2000. Organoleptic impact of 2-methoxy-3-isobutylpyrazine on red Bordeaux and Loire wines. Effect of environmental conditions on concentrations in grapes during ripening. J. Agric. Food Chem. 48(10), 4830-4834.

Sefton, M.A., 1998. Hydrolytically-released volatile secondary metabolites from a juice sample of Vitis vinifera grape cvs Merlot and Cabernet Sauvignon. Aus. J. Grape Wine Res. 4(1), 30-38.

Sefton, M.A. \& Simpson, R.F., 2005. Compounds causing cork taint and the factors affecting their transfer from natural cork closures to wine-A review. Aus. J. Grape Wine Res. 11(2), 226-240.

Sell, C., 2006. On the unpredictability of odor. Angew. Chem. Int. Ed. Engl. 45(38), 6254-6261.

Sell, C., 2014. Chemistry and the Sense of Smell. John Wiley \& Sons, Hoboken, NJ.

Shibamoto, T., 1986. Odor threshold of some pyrazines. J. Food Sci. 51(4), 1098-1099.
Shutz, M. \& Kunkee, R., 1977. Formation of hydrogen sulfide from elemental sulfur during winemaking. Am. J. Enol. Vitic. 28(3), 137-144.

Silva Teixeira, C.S., Cerqueira, N.M. \& Silva Ferreira, A.C., 2016. Unravelling the olfactory sense: From the gene to odor perception. Chem. Senses 41(2), 105-121.

Simpson, R.F, Amon, J.M. \& Daw, A.J., 1986. Off-flavour caused by guaiacol. Food Technol. Australia 38(1), 31-33.

Singh, D., Chong, H., Pitt, K., Cleary, M., Dokoozlian, N. \& Downey, M., 2011. Guaiacol and 4-methylguaiacol accumulate in wines made from smoke-affected fruit because of hydrolysis of their conjugates. Aust. J. Grape Wine Res. 17(2), 13-21

Spillman, P.J., Iland, P.G. \& Sefton, M.A., 1998. Accumulation of volatile oak compounds in a model wine stored in American and Limousin oak barrels. Aus. J. Grape Wine Res. 4(2), 67-73.

Strydom, S. \& Savage, M.J., 2016. A spatio-temporal analysis of fires in South Africa. S. Afr. J. Sci. 112(11), 1-8.

Styger, G., Prior, B. \& Bauer, F.F., 2011. Wine flavor and aroma. J. Ind. Microbiol. Biot. 38(9), 1145-1159.

Šuklje, K., Lisjak, K., Baša Česnik, H., Janeš, L., Du Toit, W., Coetzee, Z $\&$ Deloire, A., 2012. Classification of grape berries according to diameter and total soluble solids to study the effect of light and temperature on methoxypyrazine, glutathione, and hydroxycinnamate evolution during ripening of Sauvignon blanc (Vitis vinifera L.). J. Agric. Food Chem. $60(37), 9454-9461$.

Takeuchi, H., Kato, H. \& Kurahashi, T., 2013. 2,4,6-trichloroanisole is a potent suppressor of olfactory signal transduction. Proc. Natl. Acad. Sci. U.S.A. 110(40), 16235-16240. https://doi.org/10.1073/pnas.1300764110

Taylor, M., Young, T., Butzke, C.C. \& Ebeler, S.E., 2000. Supercritical fluid extraction of 2,4,6-trichloroanisole from cork stoppers. J. Agric. Food Chem. 48(6), 2208-2211.

Tempere, S., Cuzange, E., Bougeant, J.C., De Revel, G. \& Sicard, G., 2012. Explicit sensory training improves the olfactory sensitivity of wine experts. Chemosens. Percept. 5, 205-213.

Tempere, S., Cuzange, E., Schaaper, M.H., De Lescar, R., De Revel, G. \& Sicard, G., 2014. "Brett character" in wine: Is there a consensus among professional assessors? A perceptual and conceptual approach. Food Qual. Pref. 34, 29-36.

Tempere, S., Hamtat, M.L., De Revel, G. \& Sicard, G., 2016a. Comparison of the ability of wine experts and novices to identify odorant signals: A new insight in wine expertise. Aust. J. Grape Wine R. 22(2), 190-196.

Tempere, S., Schaaper, M.H., Cuzange, E., De Lescar, R., De Revel, G. \& Sicard, G., 2016b. The olfactory masking effect of ethylphenols: Characterization and elucidation of its origin. Food Qual. Pref. 50, 135-144.

Tempere, S., Schaaper, M.H., Cuzange, E., De Revel, G. \& Sicard, G., 2017. Masking of several olfactory notes by infra-threshold concentrations of 2,4,6-trichloroanisole. Chemosens. Percept. 10(3), 69-80. https://doi. org/10.1007/s12078-017-9227-5

Thomas-Danguin, T., Sinding, C., Romagny, S., El Mountassir, F., Atanasova, B., Le Berre, E. \& Coureaud, G., 2014. The perception of odor objects in everyday life: A review on the processing of odor mixtures. Front. Psychol. 2(5), 504. https://doi.org/10.3389/fpsyg.2014.00504

Van Eeden, P., 2009. Chemical, sensory and consumer analysis of cork taint in South African wines. Master's thesis, Stellenbosch University, Private Bag X1, 7602 Matieland (Stellenbosch), South Africa.

Van Wyngaard, E., Brand, J., Jacobson, D. \& Du Toit, W.J., 2014. Sensory interaction between 3-mercaptohexan-1-ol and 2-isobutyl-3methoxypyrazine in dearomatised Sauvignon blanc wine. Aust. J. Grape Wine Res. 20(2), 178-185 
Vilanova, M. \& Oliveira, J., 2012. Application of gas chromatography on the evaluation of grape and wine aroma in Atlantic viticulture (NW Iberian Peninsula). In: Bekir, S. \& Celikbicak, O. (eds). Gas Chromatography in Plant Science, Wine Technology, Toxicology and Some Specific Applications. PublTechOpen, London, UK, 109-146.

Weiss, S., 2014. The influence of grape variety on the production of volatile phenols in Portuguese wines. Master's thesis, Escola Superior de Biotecnologia, Universidade Catolica Portuguesa, Porto, Portugal.

Wilkinson, K., Ristic, R., Pinchbeck, K., Fudge, A., Singh, D., Pitt, K.M., Downey, M., Baldock, G., Hayasaka, Y., Parker, M. \& Herderich, M., 2011. Comparison of methods for the analysis of smoke related phenols and their conjugates in grapes and wine. Aust. J. Grape Wine Res. 17, S22-S28.

Wilson, C., 2017. Chemical evaluation and sensory relevance of thiols in South African Chenin blanc wines. Master's thesis, Stellenbosch University, Private Bag X1, 7602 Matieland (Stellenbosch), South Africa.

Wilson, C., Brand, J., Du Toit, W. \& Buica, A., 2018. Interaction effects of 3-mercaptohexan-1-ol (3MH), linalool and ethyl hexanoate on the aromatic profile of South African dry Chenin blanc wine by descriptive analysis (DA). S. Afr. J. Enol. Vitic. 39(2), 271-283.

Wilson, D.A., 2005. Odor perception is dynamic: Consequences for interpretation of odor maps. Chem. Senses 30(1), 105-106

Wilson, D.A. \& Stevenson, R., 2006 ( $2^{\text {nd }}$ ed). Learning to Smell. John Hopkins University Press, Baltimore.

Wilson, D.A. \& Sullivan, R.M., 2011. Cortical processing of odor objects. Neuron 72(4), 506-519.
Wirth, J., Guo, W., Baumes, R. \& Günata, Z., 2001. Volatile compounds released by enzymatic hydrolysis of glycoconjugates of leaves and grape berries from Vitis vinifera Muscat of Alexandria and Shiraz cultivars. J. Agric. Food Chem., 49(6), 2917-2923.

Wolf, L., 2018. Wildfires and wine: A detective story. C\&EN Global Enterprise, ACS Publications, Washington, D.C.

Wooding, S., 2013. Olfaction: It makes a world of scents. Curr. Biol. 23(16), R677-R679.

Wurz, D.A., Allebrandt, R., Pereira de Bem, B., Bonin, B., Reinehr, J., Tamiris Canossa, A., Rufato, L. \& Kretzschmar, A., 2017. Women have better olfactory perception for wine aromas. BIO Web Conf. 9, 04005.

Yang, W., Li, W. \& Liu, B., 2015. Odour prediction model using odour activity value from pharmaceutical industry. Austrian Contributions to Vet. Epidemiol. 8, 51-60.

Young, W.F., Horth, H., Ogden, T., Arnott, M. \& Crane, R., 1996. Taste and odour threshold concentrations of potential potable water contaminants. Water Res. 30(2), 331-340.

Zhang, L., Zhao, L., Wang, H., Zhi, R., Shi, B. \& Xie, N., 2016. Determination of recognition threshold and just noticeable difference in the sensory perception of pungency of Zanthoxylum bangeanum. Int. J. Food Prop. 19(5), 1044-1052.

Zoecklein, B.W., Fugelsang, K.C., Gump, B.H. \& Nury, F.S., 1995. Volatile acidity. In: Wine Analysis and Production. Springer US, Boston, MA., 192198. 